\title{
Learning of courtship components in Drosophila mercatorum (Paterson \& Wheller) (Diptera, Drosophilidae)
}

\author{
Andrei Polejack ${ }^{1} \&$ Rosana Tidon ${ }^{2}$
}

${ }^{1}$ Conselho Nacional de Desenvolvimento Científico e Tecnológico (CNPq) SEPN 509 - Bloco A - 3 andar, sala 306. 70750-510. Brasília-DF. asodre@cnpq.br

${ }^{2}$ Universidade de Brasília, Instituto de Biologia-GEM, Caixa Postal 04457, 70904-970, Brasília-DF. rotidon@unb.br (corresponding author)

\begin{abstract}
Learning of courtship components in Drosophila mercatorum (Paterson \& Wheller) (Diptera, Drosophilidae). In Drosophila, courtship is an elaborate sequence of behavioural patterns that enables the flies to identify conspecific mates from those of closely related species. This is important because drosophilids usually gather in feeding sites, where males of various species court females vigorously. We investigated the effects of previous experience on D. mercatorum courtship, by testing if virgin males learn to improve their courtship by observing other flies (social learning), or by adjusting their pre-existent behaviour based on previous experiences (facilitation). Behaviours recorded in a controlled environment were courtship latency, courtship (orientation, tapping and wing vibration), mating and other behaviours not related to sexual activities. This study demonstrated that males of D. mercatorum were capable of improving their mating ability based on prior experiences, but they had no social learning on the development of courtship.
\end{abstract}

KEYWORDS. Flies; repleta group; sexual behaviour.

RESUMO. Aprendizado de corte sexual em Drosophila mercatorum (Paterson \& Wheller) (Diptera, Drosophilidae). Em Drosophila, a corte sexual consiste em uma elaborada sequiência de padrões comportamentais que possibilita às moscas reconhecer parceiros conspecíficos dentre indivíduos de outras espécies. Essa discriminação é importante uma vez que drosofilídeos geralmente se agregam em sítios de alimentação, onde machos de diversas espécies cortejam as fêmeas vigorosamente. Neste estudo, testamos se machos virgens aprimoram seu comportamento de corte mediante a observação do cortejo de outras moscas da população (aprendizado social), ou mediante experiências próprias anteriores (facilitação). O comportamento de corte das moscas, observado em ambiente controlado, foi registrado com relação aos seguintes componentes: latência da corte, duração da corte (orientação, "tapping" e vibração das asas), cópula, e outros comportamentos não relacionados à corte sexual. Os resultados aqui obtidos sugerem que machos de D. mercatorum são capazes de aprimorar sua habilidade de cortejar fêmeas em função de experiências próprias anteriores, mas não encontramos nenhuma evidência de aprendizado social para esse comportamento.

PALAVRAS-CHAVE. Comportamento sexual; grupo repleta; moscas.

Drosophila is a widely used animal model in various biological fields, including learning and memory studies. Many types of learning have been successfully demonstrated in these flies, and these results are increasing our understanding of the genetic basis of plastic behaviours (Wang et al. 2003; Manolli et al. 2005; Quinn 2006). Courtship behaviour is one of the most essential and complex behaviours in Drosophila, and presents an interesting paradigm to address evolutionary studies because of its immediate connection to reproduction (Spieth 1974; Hall 1994). Since there should be a high selection pressure for males to recognize and access putative mates (Reif et al. 2002), the ability to learn how to court females and mate should have an important role in a male fly's fitness.

Mating ability in drosophilids seems to be influenced by various factors, including prior experience and associative learning behaviour (Greenspan \& Ferveur 2000). However, the manner by which social contact affects courtship is not completely clear. In a series of investigations into the development of sexual behaviour in semispecies of $D$. paulistorum, Kim et al. (1992, 1996a,b) showed that discriminatory abilities were reduced when individuals were totally isolated from their consemispecifics, but significantly increased when two intersterile semispecies were brought together. In the same way, $D$. silvestris kept in isolation after hatching are less successful in mating than those reared in groups (Sene 1977). On the other hand, males of D. subobscura similarly isolated exhibited higher frequencies of mating (Maynard Smith 1956). Although the influence of social experience is relatively well known in some vertebrate groups (Sakata et al. 2002 and references therein), little is known about insects.

In this study, we tested two hypotheses about the effects of previous experiences on courtship behaviour in Drosophila. The first hypothesis, social learning, presupposes that a male can learn how to court from the observation of more experienced males. Our second hypothesis, facilitation, assumes that Drosophila males can improve their courtship performance simply by the repetition of previous behaviours, i.e., they can learn throughout individual experience.

\section{MATERIALS AND METHODS}

Drosophila mercatorum (Paterson \& Wheller 1942), a generalist species highly competitive for its food resources (Pereira et al. 1983), is one of the most abundant neotropical 
drosophilids in areas of open vegetation in South America (Vilela et al. 1983; Tidon 2006). It is also the only neotropical species that reached the sub cosmopolitan status of distribution, since it has colonized the northern hemisphere (Neartic and Paleartic regions), Africa, India, and Hawaii. In this study, we used the D33F43 strain of D. mercatorum pararepleta, collected in Central Brazil (Manfrin et al. 1999).

Subjects lightly anaesthetized with $\mathrm{CO}_{2}$ were randomly collected soon after their emergence from the pupae, and left for sexual maturation for seven days. These flies were kept in glass vials partly filled with banana-agar medium at $25 \pm 1^{\circ} \mathrm{C}$ in a $12 \mathrm{~L} / 12 \mathrm{D}$ photoperiod. Individual males were kept in isolation, while females aged communally.

Behaviours were observed in two different types of chambers, modified from Sene and Manfrin (1998). For the tests of social learning, we used an observation chamber, which has a discontinuous barrier that allows the free input of visual, odorous and acoustic stimuli between the experimental subject and the couple being observed, but does not allow the subject to interfere with the couple. For the tests of facilitation, we used a nuptial chamber, which has no barriers so that the couple could freely exercise courtship and mating. A scheme of the observational chamber is available in Polejack and Tidon (2002), at the Drosophila Information Service homepage (http:/ /www.ou.edu/journals/dis/).

Experimental design. We conducted experiments when the flies were more active: early in the morning $(8 \mathrm{a} . \mathrm{m}$.$) and late in$ the evening ( 6 p.m.). In all experiments, the subjects were transferred from the vials to the chambers using an aspirator, rather than anaesthesia. During the tests, four main categories of behaviours were observed: [1] courtship latency, which is the time taken by the male to initiate courtship of the female after its introduction into the chamber, [2] courtship duration, the amount of time that mates display the following courtship elements: orientation, tapping and wing vibration; [3] mating; and [4] other behaviours not related to courtship itself, such as grooming, walking, proboscide extension and resting. For definitions of these courtship elements, see Spieth (1968) and Cobb et al. (1985). The observation was terminated once the female expelled the mounting male, or no mating occurs after 15 minutes. After each experiment, we carefully washed the chambers with $70 \%$ alcohol to eliminate the effects of pheromones left by the flies. Data were collected with ethological analyses software (Etholog version 2.2.5; Ottoni 1999).

In order to investigate the ability of flies to learn, sexually mature virgin males went through the following experimental stages:

Observation. The observer male was placed in the observation chamber for 10 minutes, to be habituated in the environment (Gisquet-Verrier et al. 1989). Thereafter, the demonstrator, a male that had at least one previous successful mating, was introduced in the other side of the chamber. Then, a virgin female randomly chosen from the same population of the males was added to the demonstrator, and the test started.
During the observation, the observer male was able to watch but did not interfere in the courtship and mating of the demonstrator. At the end of the test, the males and female were individually aspirated and conducted to the next stage of the experiment.

$1^{\text {st }}$ Trial. Immediately after the first stage, the observer was introduced into the nuptial chamber and, after a 10 minutes period during which the male habituated to its new environment, another randomly chosen virgin female was introduced into the chamber and the experimental session began. After mating was completed, we aspirated this male and returned him to his original vial, where he could rest for the second trial.

$2^{\text {nd }}$ Trial. Twenty-four hours later, the observer could court and mate with another virgin female, just as in the first trial. This female had the same age (about 8 days old) as the one used before.

$3^{\text {rd }}$ Trial. Some subjects that had already successfully completed the two previous trials were used as demonstrators. This third mating was also recorded in order to compare it with the male's previous two performances. Thus, we obtained a third mating with comparable behavior parameters that allowed an analysis of learning patterns related to facilitation. If the differences found between the two subsequent matings resulted from the male's experience, a third mating by the male could indicate possible patterns in the measured behaviors.

Control subjects were randomly collected from the same population of the observers and went through the same stages, except that during the first stage they did not observe a mating couple, but a virgin female alone. Sessions followed the same procedures and were conducted during the same periods of the day.

Statistical analysis. We analyzed 40 experimental observers (E) and 37 control (C) males, among which $20 \%$ of experimental males (eight flies) and 27\% of control males (ten flies) did not mate, and were excluded from the analyses. Since none of the variables measured showed a normal distribution (D'AgostinoPearson test of normality), we used the Mann-Whitey U test (Zar 1999).

\section{RESULTS}

Table I summarizes the durations of the behavioural elements, in the experimental and control groups, during the three successive trials of this experiment. It shows also the results and significance, of comparisons between pairs of trials, given by the Mann-Whitney U test. Details about these results are given below.

Social learning. There were no significant differences between experimental and control males (Trials 1+2) in session duration $(\mathrm{U}=1849, \mathrm{p}=0.51)$, courtship latency $(\mathrm{U}=2043.5$, $\mathrm{p}=0.09)$, courtship $(\mathrm{U}=1821.5, \mathrm{p}=0.61)$, mating $(\mathrm{U}=1625, \mathrm{p}=0.58)$, and other behaviours $(\mathrm{U}=1591, \mathrm{p}=0.46)$. The same was found when testing courtship components such as orientation 
Table I. Duration of the behaviours for the control (C) and the experimental (E) groups in the three subsequent trials of the experiment (mean $\pm \mathrm{SE}$ ), and comparison among them by means of the Mann-Whitney U-test ( $\alpha=5 \%, 1 \mathrm{df})$.

\begin{tabular}{|c|c|c|c|c|c|c|c|c|}
\hline & \multicolumn{5}{|c|}{ Duration of the behaviors (in seconds) } & \multicolumn{3}{|c|}{ U values among trials } \\
\hline & Trial 1 & & Trial 2 & & Trial 3 & Trial $1 \times 2$ & Trial $2 X$ & Trial $1 \times 3$ \\
\hline & C $\quad(n=27)$ & E $\quad(n=32)$ & C $\quad(n=27)$ & E $\quad(n=32)$ & $C+E \quad(n=21)$ & & & \\
\hline Session duration & $314.37 \pm 22.02$ & $312.29 \pm 33.04$ & $323.83 \pm 24.39$ & $350.85 \pm 34.03$ & $278.54 \pm 21.21$ & 1533 & 750 & 662 \\
\hline Courtship latency & $44.82 \pm 8.22$ & $35.55 \pm 9.01$ & $45.23 \pm 13.68$ & $20.50 \pm 4.40$ & $18.14 \pm 5.45$ & $2118.5^{*}$ & $798.5^{*}$ & $884 * *$ \\
\hline Courtship duration & $46.44 \pm 10.66$ & $38.37 \pm 8.33$ & $66.94 \pm 15.00$ & $73.50 \pm 12.00$ & $56.83 \pm 9.89$ & $1334 *$ & 666 & 481 \\
\hline (1) Orientation & $37.32 \pm 9.59$ & $26.42 \pm 6.76$ & $56.85 \pm 13.81$ & $54.29 \pm 8.90$ & $48.93 \pm 9.02$ & 1619 & 768 & 716.5 \\
\hline (2) Tapping & $2.97 \pm 0.63$ & $2.50 \pm 0.52$ & $3.89 \pm 0.63$ & $5.60 \pm 1.24$ & $3.30 \pm 0.75$ & $1279 * *$ & 644 & 456 \\
\hline (3) Wing Vibration & $6.14 \pm 0.98$ & $9.44 \pm 2.22$ & $6.19 \pm 1.12$ & $13.60 \pm 3.74$ & $4.59 \pm 0.90$ & $1277 * *$ & 720 & 569 \\
\hline Copulation Duration & $166.94 \pm 10.23$ & $180.07 \pm 14.28$ & $164.84 \pm 7.89$ & $169.37 \pm 7.42$ & $157.96 \pm 7.48$ & 1720 & 723 & 698 \\
\hline Other Behaviours & $56.18 \pm 13.53$ & $58.31 \pm 15.10$ & $46.83 \pm 11.20$ & $87.50 \pm 23.27$ & $45.64 \pm 11.34$ & 1543 & 695 & 602.5 \\
\hline
\end{tabular}

$* . \mathrm{P} \leq 0,05 ; * * . \mathrm{P} \leq 0,001$

$(\mathrm{U}=1899.5, \mathrm{p}=0.35)$, tapping $(\mathrm{U}=1808.5, \mathrm{p}=0.66)$ and wing vibration $(\mathrm{U}=1580, \mathrm{p}=0.42)$. These results were confirmed in the analysis of Trials 1 and 2 independently.

Facilitation. Since no distinctions between experimental and control males were found in the social learning experiment, we aggregated them in one population $(\mathrm{N}=59)$ to compare their performances in Trials 1 and 2. Twenty-one subjects that had already successfully completed two matings were used for the $3^{\text {rd }}$ Trial.

The elements that did not differ among the three trials were session duration, mating duration, and other behaviours (Table I). However, courtship latency was significantly shorter for subsequent matings (Fig 1A) and total courtship duration was significantly longer between mating 1 and 2 , but not between mating 2 and 3, nor between 1 and 3 (Fig. 1B).

\section{DISCUSSION}

Social learning in Drosophila mercatorum. Our results suggest that the social learning of sexual behaviours in Drosophila mercatorum did not occur in the conditions of this experiment, since experimental and control males did not differ in the duration of any of the measured behaviours.

One can speculate that drosophilids, which gather in groups in feeding sites (Powell 1997), should have the opportunity to learn from others. However, several fly species in different developmental stages coexist in these places and it is common to see males courting females from other species. Thus, it would not be advantageous to learn variations in courtship from other species because these could reduce the receptivity from conspecific females. Therefore, in the ecological context of Drosophila, social learning would not represent any advantage. Cobb and Ferveur (1995) point out that although it might appear that courtship consists primarily of visual elements and that the male is the more active partner, in reality the pre-mating interaction between male and female flies involves an exchange of information and a dynamic mutual stimulation involving various sensory modalities.
However, since there has been little ecological and evolutionary research on learning in the context of sexual behaviour in insects, the traditional view that insects have little opportunity to learn about courtship and mating has been challenged, and this is considered a fruitful area of research (Dukas 2005).

Facilitation. To look for behavioural changes indicating learning through experience in $D$. mercatorum, we compared male performances in successive matings. We found changes in two behavioural components: courtship latency and courtship duration.

Courtship latency was shorter in the observer's second trial, 24 hours after the first one, suggesting that males learned, through facilitation, to begin courtship sooner. This result is supported by a decline in courtship latency in a third trial, indicating that the more experienced the male, the faster it will initiate courting (Figure 1A). Our results are supported by experiments using Drosophila silvestris (Boake \& Konigsberg 1998) and D. melanogaster (Dukas 2005), where experienced
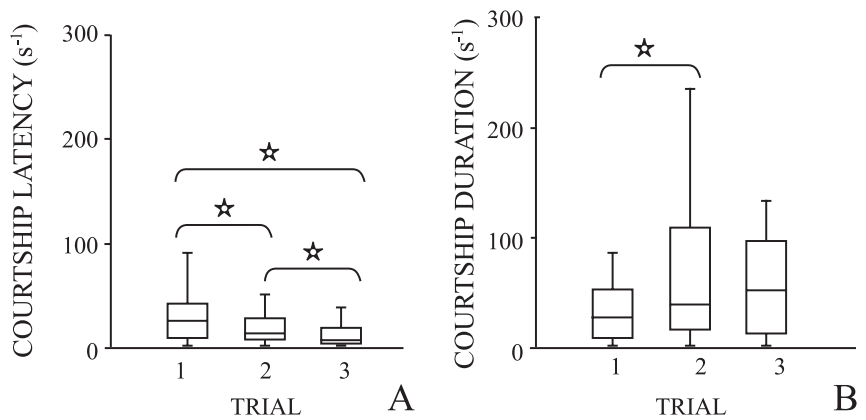

Fig.1. Courtship latency (A) and courtship duration (B) in successive mating trials of Drosophila mercatorum (1: first mating trial, 2: 24 hours later, 3: third mating trial). Boxes show the range within which the central $50 \%$ of the values fall, with the box hinges (borders) at the first and third quartiles. The central horizontal lines show the median values (in seconds). The whiskers show the range of values that fall within the inner fences. $(*)=p<0.05$. 
males begin to court virgin females sooner than do virgin males. In natural environments, males tend to spend a good part of their time courting females while they are foraging. The cost of this behaviour may be high because they must stop feeding and are more exposed to predators. Therefore, it is advantageous for males to test and discover potential partners in the most effective way (Dukas 1998), and the prior experience that a fly receives changes its subsequent mating ability (Greenspan \& Ferveur 2000).

Although males in our experiment began courtship more rapidly in repeated trials, they devoted significantly more time courting females in the second trial. If facilitation is the refinement of the function, it is expected that males spend the smallest amount of energy to reach the objective of courtship: egg fertilization. However, the proportion of time devoted to courtship is significantly influenced by females in two ways (Boake \& Hoikkala 1995; Boake et al. 2000). First, there is a reduction in the females' receptivity when males carry a feminine pheromone resulting from contact with females in a previous mating, which may indicate that it has less sperm than a virgin male (Scott et al. 1988). In D. melanogaster, virgin males are preferred by virgin females, probably because these recognize the male with larger amount of sperm available (Markow et al.1978). Second, speciation and sexual selection models emphasize the importance of the number of males sampled by females (Boake et al. 2000). Previous matings of a female with a certain type of male change its attitude in favour of the sampled male, being this preference frequency dependent. Females usually demonstrate preference for the rare type, less frequent in the population (Knoppien 1985). Thus, it is possible that courtship increased in the second trial due to a decrease in female receptivity: males with pheromone residues from a previous mating were forced to invest more energy pursuing and fumbling the female that possibly accepted them only as the result of a no-choice experiment. Courtship duration in the second and third trials was very similar, indicating that the female receptivity continued the same (Figure 1B), that is, males were forced to pursue the females for the same amount of time after their sexual debut.

In conclusion, this study demonstrated that males of Drosophila mercatorum pararepleta were capable of changing their subsequent mating ability based on prior experiences, but social learning did not play any role on the development of courtship. Behavior is likely to be the most context-dependent of all phenotypes (Greenspan \& Ferveur 2000), and researchers have expended considerable effort in exploring the processes that underlie social learning. Even so, the exact contexts under which animals copy others remain unexplored (Laland 2004).

Acknowledgments. We thank Y-K Kim, R. Macedo, R.C. Lewontin and A.C. Franco for their comments on earlier versions of the manuscript. This study was supported by the Conselho Nacional de Desenvolvimento Cientifico e Tecnológico (CNPq), Animal Behavior Society, and Universidade de Brasília.

\section{REFERENCES}

Boake, C. R. B. \& A. Hoikkala. 1995. Courtship behaviour and mating success of wild-caught Drosophila silvestris males. Animal Behaviour 49: 1303-1313.

Boake, C. R. B. \& L. Konigsberg. 1998. Inheritance of male courtship behavior, aggressive success, and body size in Drosophila silvestris. Evolution 52: 1487-1492.

Boake, C. R. B.; D. K. Andreadis \& A. Witzel. 2000. Behavioural isolation between two closely related Hawaiian Drosophila species: the role of courtship. Animal Behaviour 60: 495-501.

Cobb M. \& J. F. Ferveur. 1995. Evolution and genetic control of mate recognition and stimulation in Drosophila. Behavioural Processes 35: 35-54.

Cobb, M.; K. Connolly \& B. Burnet. 1985. Courtship behavior in the melanogaster species subgroup of Drosophila. Behaviour 95: 203231 .

Dukas, R. 1998. Evolutionary ecology of learning, p. 129-174. In: R. Dukas (ed.). Cognitive Ecology: The Evolutionary Ecology of Information Processing and Decision Making. Univ. Chicago Press.

Dukas R. 2005. Experience improves courtship in male fruit flies. Animal Behaviour 69: 1203-1209.

Gisquet-Verrier, P.; A. Dekeyne \& T. Alexinsky. 1989. Differential effects of several retrieval cues over time: evidence for timedependent reorganization of memory. Animal Learning Behaviour 17: 394-408.

Greenspan, R. J. \& J. F. Ferveur. 2000. Courtship in Drosophila. Annual Review of Genetics 34: 205-232.

Hall, J. C. 1994. The mating of a fly. Science 264: 1702-1714.

Kim, Y-K.; L. Ehrman \& H. R. Koepfer. 1992. Developmental isolation and subsequent adult behavior of Drosophila paulistorum. I. Survey of the six semispecies. Behavior Genetics 22: 545-556.

Kim, Y-K.; L. Ehrman \& H. R. Koepfer. 1996a. Developmental isolation and subsequent adult behavior of Drosophila paulistorum. II. Prior experience. Behavior Genetics 26: 15-25.

Kim, Y-K.; H. R. Koepfer \& L. Ehrman. 1996b. Developmental isolation and subsequent adult behavior of Drosophila paulistorum. III. Alternative rearing. Behavior Genetics 26: 27-37.

Knoppien, P. 1985. Rare male mating advantage: a review. Biological Reviews 60: 81- 117 .

Laland, K. N. 2004. Social learning strategies. Learning and Behavior 32: $4-14$.

Manfrin M. H.; R. Tidon-Sklorz \& F. M. Sene. 1999. Drosophila female receptivity to males with different sound parameters values. Drosophila Information Service 82: 81-84.

Manoli D. S.; M. Foss; A. Villella; B. J. Taylor; J. C. Hall \& B. S. Baker. 2005. Male-specific fruitless specifies the neural substrates of Drosophila courtship behaviour. Nature 436: 395-400.

Markow, T. A.; M. Quaid \& S. Kerr. 1978. Male mating experience and competitive courtship success in Drosophila melanogaster. Nature 276: $821-822$.

Maynard Smith, J. 1956. Fertility, mating behavior and sexual selection in Drosophila subobscura. Journal of Genetics 54: 261-279.

Ottoni, E. B. 1999. Etholog v. 2.2.5. Laboratory of Comparative Psychology and Ethology. Universidade de São Paulo, São Paulo, Brasil. Software.

Patterson, J. T. \& M. R. Wheeler. 1942. Description of new species of the subgenera Hirtodrosophila and Drosophila. University of Texas Publications 4213: 67-109.

Pereira, M. A. Q. R.; C. R. Vilela \& F. M. Sene. 1983. Notes on breeding and feeding sites of some species of the repleta group of the genus Drosophila (Diptera, Drosophilidae). Ciência e Cultura 35: 1313-1319.

Polejack, A. \& R. Tidon. 2002. A new method for assessing social learning in Drosophila. Drosophila Information Service 85: 120 . 
Powell, J. R. 1997. Progress and Prospects in Evolutionary Biology: the Drosophila Model. Oxford University Press, New York, $562 \mathrm{p}$.

Quinn W. G. (2006) Neurobiology - Memories of a fruitfly. Nature 439: $546-548$.

Reif, M.; L. Linsenmair \& M. Heisenberg. 2002. Evolutionary significance of courtship conditioning in Drosophila melanogaster. Animal Behaviour 36: 1164-1173.

Sakata, J. T.; A. Gupta; C. Chien-Pei \& D. Crews. 2002. Social experience affects territorial and reproductive behaviours in male leopard geckos, Eublepharis macularius. Animal Behaviour 63: 487493.

Scott, D.; R. C. Richmond \& D. A. Carlson. 1988. Pheromones exchanged during mating: a mechanism for mate assessment in Drosophila. Animal Behaviour 36: 1164-1173.

Sene, F. M. 1977. Effect of social isolation on behavior of Drosophila silvestris from Hawaii. Proceedings of the Hawaiian Entomological Society 22: 469-474.

Sene, F. M. \& M. H. Manfrin. 1998. A chamber to record the courtship sound in Drosophila. Drosophila Information Service 81: $203-$ 204.

Spieth, H. T. 1968. Evolutionary implications of sexual behavior in Drosophila. Evolutionary Biology 2: 157-193.

Spieth, H. T. 1974. Courtship behavior in Drosophila. Annual Review of Entomology 19: 385-405.

Tidon, R. 2006. Relationships between drosophilids (Diptera, Drosophilidae) and the environment in two contrasting tropical vegetations. Biological Journal of the Linnean Society 87: 233-247.

Vilela C. R.; M. A. Q. R. Pereira \& F. M. Sene. 1983. Preliminary data on geographical distribution of Drosophila species within morphoclimatic domains in Brazil. II. The repleta group. Ciência e Cultura 35: 66-70.

Wang S. P.; Li Y.; Feng C. H. \& A. K. Guo. 2003 Dissociation of visual associative and motor learning in Drosophila at the flight simulator. Behavioural Processes 64: 57-70.

Zar, J. H. 1999. Biostatistical Analysis. $4^{\text {th }}$ ed. Prentice-Hall, Inc., $929 \mathrm{p}$.

Received 13/09/2006; accepted 08/12/2006 